\title{
1-Chloro-1,3-butadiene Copolymers V. Composition and Compositional Distribution in the Copolymer with Styrene Studied by Thin-Layer Chromatography
}

\author{
Shinzo KohJiYa, Kazuo Iwata, Shinzo Yamashita, \\ Takeaki MIYAMOTO, ${ }^{*}$ and HIROSHI INAGAKI* \\ Department of Chemistry, Kyoto Institute of Technology, \\ Matsugasaki, Kyoto 606, Japan \\ *Institute for Chemical Research, Kyoto University, Uji \\ 611, Japan
}

(Received June 23, 1983)

\begin{abstract}
The copolymer of 1-chloro-1,3-butadiene (CB) and styrene (St) was synthesized and its composition and distribution in poly(CB-co-St) were investigated by thin-layer chromatography (TLC). The concentration gradient development method of a tetrahydrofuran-cyclohexane mixture was useful for separating the copolymer into its components. Resolution by molecular weight was not significant under the present conditions. The experimental results on the compositional distribution of poly(CB-co-St)s obtained at high conversion were in close agreement with the values calculated from the monomer reactivity ratios and conversion. Also, the composition of the copolymers having a CB content too small for ordinary elemental analysis to be applicable could be assayed by TLC. The observed CB content was below $1 \mathrm{~mol} \%$, and agreed well with that calculated.
\end{abstract}

KEY WORDS 1-Chloro-1,3-butadiene / Styrene / Copolymer / Compositional Distribution / Compositional Heterogeneity / Thin Layer Chromatography /

The preceding paper ${ }^{1}$ in this series suggested that the characterization of poly(1-chloro-1,3-butadieneco-styrene) was important for understanding the polymer reactions of the copolymer. The bulk copolymerization of 1-chloro-1,3-butadiene (CB) with styrene (St) was carried out, and the monomer reactivity ratios and factors influencing the molecular weight of poly(CB-co-St) were discussed ${ }^{1}$ in that paper. In the present study, the compositional distribution in poly(CB-co-St) is investigated by thin-layer chromatography (TLC). Copolymers are usually polydisperse not only in molecular weights but in chemical compositions; i.e., they show compositional heterogeneity. Data on the compositional distribution of poly(CB-co-St) may be useful for two reasons: the distribution can affect the reactivity of CB-St copolymer in polymer reactions where chlorine in $\mathrm{CB}$ unit is involved, and provides experimental proof for the theory of copolymerization kinetics (terminal model for CB-St).
Since TLC is a very feasible method for determining the compositional distribution in copolymers, ${ }^{2}$ and TLC had been successfully applied to the compositional heterogeneity of St-acrylate copolymers, ${ }^{2,3}$ it was carried out on poly(CB-co-St). Also, we have found TLC to be remarkably sensitive for detecting small amount of CB units in poly(CB-co-St). ${ }^{4}$

\section{EXPERIMENTAL}

\section{Polymerization}

CB, St, and 2,2'-azobisisobutyronitrile (AIBN) were purified and copolymerizations were carried out as described in the preceding paper. ${ }^{1}$ The poly(CB-co-St)s employed in the present study are listed in Table I. Copolymers No. $1-5$ were obtained at conversions lower than $10 \%$, and used as standard samples for TLC analysis. No. 6-9 were obtained at much higher conversions and their 


\section{S. KoHJIYA et al.}

Table I. Poly(CB-co-St)s used in the present study ${ }^{\mathrm{a}}$

\begin{tabular}{|c|c|c|c|c|c|c|}
\hline \multirow[t]{2}{*}{ No. } & \multirow{2}{*}{$\begin{array}{l}\begin{array}{l}\text { CB content in } \\
\text { monomer feed }\end{array} \\
\mathrm{mol} \%\end{array}$} & \multirow{2}{*}{$\frac{[\mathrm{M}]^{\mathrm{b}}}{[\mathrm{AIBN}]}$} & \multirow{2}{*}{$\begin{array}{c}\begin{array}{c}\text { Polymerization } \\
\text { time }\end{array} \\
\mathrm{h}\end{array}$} & \multirow{2}{*}{$\frac{\text { Conversion }}{\%}$} & \multirow{2}{*}{$\frac{\begin{array}{c}\text { CB content } \\
\text { in copolymer }\end{array}}{\mathrm{mol} \%}$} & \multirow{2}{*}{$\begin{array}{l}\text { Molecula } \\
\text { weight }^{d}\end{array}$} \\
\hline & & & & & & \\
\hline 1 & 0.180 & 200 & 0.50 & 6.92 & 1.55 & 60,000 \\
\hline 2 & 0.450 & 200 & 0.50 & 6.13 & 2.11 & 46,700 \\
\hline 3 & 1.33 & 200 & 0.70 & 6.56 & 4.58 & 36,100 \\
\hline 4 & 4.20 & 200 & 1.0 & 5.53 & 12.8 & 25,700 \\
\hline 5 & 9.44 & 200 & 2.0 & 7.47 & 24.4 & 23,300 \\
\hline 6 & 2.34 & 200 & 19 & 80 & 2.95 & 59,900 \\
\hline 7 & 3.51 & 200 & 19 & 75 & 4.70 & 58,700 \\
\hline 8 & 4.67 & 200 & 19 & 70 & 6.60 & 50,700 \\
\hline 9 & 5.83 & 200 & 19 & 70 & 7.84 & 45,100 \\
\hline 10 & 0.102 & 500 & 4.0 & 32.5 & 0 & $72,400^{\mathrm{e}}$ \\
\hline 11 & 0.156 & 500 & 4.0 & 32.1 & 0 & 71,400 \\
\hline
\end{tabular}

a Bulk polymerization at $70^{\circ} \mathrm{C}$.

b Ratio of [total monomers] to [AIBN].

c From elemental analysis of chlorine.

d Number-average molecular weight from membrane osmometry.

e From gel permeation chromatography, molecular weight at peak position was $79,000, M_{n}=54,800$ and $M_{w}=$ 103,700 where $M_{n}$ and $M_{w}$ are the number-average and weight-average molecular weights, respectively. The $M_{w} / M_{n}$ ratio was 1.90 .

Table II. TLC development with single solvents

\begin{tabular}{|c|c|c|c|c|c|c|}
\hline \multirow{2}{*}{ Developer } & \multirow{2}{*}{$\varepsilon^{\mathrm{oa}}$} & \multirow{2}{*}{$\begin{array}{c}\text { Dielectric } \\
\text { constnat }\end{array}$} & \multicolumn{4}{|c|}{$R f$} \\
\hline & & & $\mathrm{PSt}^{\mathrm{b}}$ & $2^{c}$ & $3^{c}$ & $4^{c}$ \\
\hline Cyclohexane & 0.04 & 2.02 & 0 & 0 & 0 & 0 \\
\hline Carbon tetrachloride & 0.16 & 2.22 & 0 & 0 & 0 & 0 \\
\hline$p$-Xylene & 0.26 & 2.27 & 1 & $1(t)^{d}$ & $0(\mathrm{t})$ & 0 \\
\hline Benzene & 0.32 & 2.28 & 1 & 1 & $1(t)$ & $1(\mathrm{t})$ \\
\hline Chloroform & 0.40 & 4.62 & 1 & 1 & $1(t)$ & $1(t)$ \\
\hline $\mathrm{THF}^{\mathrm{e}}$ & 0.45 & 7.42 & 1 & 1 & 1 & 1 \\
\hline Acetone & 0.56 & 20.70 & $0^{\mathrm{f}}$ & $0^{f}$ & $0^{\mathrm{f}}$ & $0^{\mathrm{f}}$ \\
\hline
\end{tabular}

a Solvent strength parameter for alumina. ${ }^{5}$

b Standard polystyrene with a molecular weight of 37,000 .

c Poly(CB-co-St)s. See Table I.

d (t) indicates spot tailing.

e Tetrahydrofuran.

f $R f=0$, since acetone was not a solvent for these polymers.

compositional heterogeneities were also studied. No. 10 and 11 were copolymers whose CB content was so small that ordinary elemental analysis of chlorine was not applicable to determine the composition.

\section{Polymer Characterization}

The number-average molecular weights of the polymers were determined with a Knauer membrane osmometer and gel permeation chromatography, by a Toyo Soda HLC-801A: eluent, tetra-

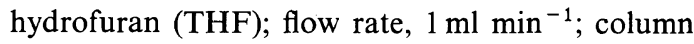
temperature, $40^{\circ} \mathrm{C}$.

\section{TLC Experiments}

Kieselgel H Typ 60 (E. Merk AG) was used as the 
Table III. $R f$ values for benzene-carbon tetrachloride and THF-cyclohexane mixtures

\begin{tabular}{|c|c|c|c|c|c|c|}
\hline \multicolumn{2}{|c|}{ Developer/ml } & \multicolumn{5}{|c|}{$R f$} \\
\hline Benzene & $\begin{array}{c}\text { Carbon } \\
\text { tetrachloride }\end{array}$ & $\mathrm{PSt}^{\mathrm{a}}$ & $2^{b}$ & $3^{b}$ & $4^{b}$ & $5^{\mathrm{b}}$ \\
\hline 40 & 10 & 1 & 1 & 1 & 1 & 1 \\
\hline 40 & 15 & 1 & $1(t)^{c}$ & $1(\mathrm{t})$ & $0(\mathrm{t})$ & $0(\mathrm{t})$ \\
\hline 40 & 20 & 1 & $1(t)$ & $1(t)$ & $0(\mathrm{t})$ & $0(\mathrm{t})$ \\
\hline 40 & 30 & 1 & $0(\mathrm{t})$ & $0(\mathrm{t})$ & $0(\mathrm{t})$ & $0(\mathrm{t})$ \\
\hline THF & Cyclohexane & & & & & \\
\hline 20 & 40 & 1 & 1 & 1 & 1 & 1 \\
\hline 10 & 40 & $0.4-0.6$ & $0-0.5(\mathrm{t})$ & $0-0.5(\mathrm{t})$ & $0-0.5(\mathrm{t})$ & $0-0.5(\mathrm{t})$ \\
\hline
\end{tabular}

a, b, c See footnotes b, c, d in Table II.

stationary phase, since silica gel, very popular in TLC, has an absorption capacity often too strong for polymers. Kieselgel was spread on a glass plate $(20 \mathrm{~cm} \times 10 \mathrm{~cm})$, its thickness adjusted to $0.4 \mathrm{~mm}$ and then activated at $110^{\circ} \mathrm{C}$ for $1 \mathrm{~h}$ just before use. The polymer in the chloroform solution (usually $5-10 \mu$ g polymer) was applied on to the plate and its development proceeded in a solvent tank (50$90 \mathrm{ml}$ solvent) at room temperature. The development distance was $10 \mathrm{~cm}$ and Thymol Blue-sulfuric acid was used for visualization.

\section{RESULTS AND DISCUSSION}

\section{TLC Development with Single Solvents and Their Mixtures}

Seven solvents with different solvent strength parameters $\varepsilon^{\circ 5}$ were used as developers for the polymer samples, polystyrene (PSt) and poly(CB$c o$-St)s. The results are summarized in Table II. The $R f$ value was found to be either 0 or 1 sometimes with tailing and there was no intermediate value. Thus, no single solvent was adequate to separate the copolymer into its constituents. An examination of the binary mixtures of these developers showed that benzene-carbon tetrachloride, THF-carbon tetrachloride, chloroform-carbon tetrachloride, and chloroform-cyclohexane gave no satisfactory results, though THF-cyclohexane was somewhat promising. Some of the results on binary mixtures are shown in Table III. THF-cyclohexane has the largest $\Delta \varepsilon^{\circ}$ (difference of $\varepsilon^{\circ}$, see Table II), due perhaps to its being the most suitable for com-
Table IV. Mixing mode in the THF-cyclohexane concentration gradient development ${ }^{\mathrm{a}}$

\begin{tabular}{|c|c|c|}
\hline Distance from the origin ${ }^{b}$ & THF & Cyclohexane \\
\hline $\mathrm{cm}$ & $\mathrm{ml}$ & $\mathrm{ml}$ \\
\hline 0 & 0 & 50 \\
\hline 2 & 8 & 50 \\
\hline 4 & 16 & 50 \\
\hline 6 & 24 & 50 \\
\hline 8 & 32 & 50 \\
\hline
\end{tabular}

a At room temperature: Stationary phase; Kieselgel $\mathbf{H}$ Typ 60, $0.4 \mathrm{~mm}$.

b Development was conducted at a distance of $10 \mathrm{~cm}$ from the origin.

position separation. When $\Delta \varepsilon^{\circ}$ is small, separation by molecular weight is often done in the TLC of polymers. $^{3}$

\section{Concentration Gradient Development}

On the basis of the above results, the concentration gradient method for THF-cyclohexane was applied to the present problem and was found very effective for several low molecular weight compound $s^{6}$ and St-acrylate copolymers ${ }^{2}$ not separatable with single solvents or binary mixtures. After many preliminary experiments with various solvent compositions, the mixing mode shown in Table IV was adopted.

Figure 1 shows the chromatogram of samples No. 7, No. 2-5, and PSt by the concentration gradient method. In Figure 1, No. $2-5$ gave smaller spots, 


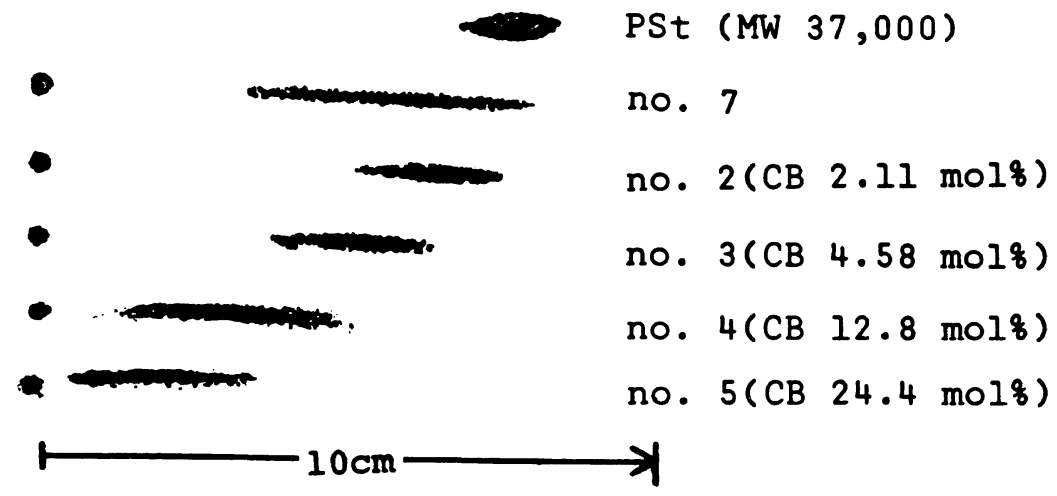

Figure 1. TLC of poly(CB-co-St)s by the concentration gradient method: PSt is a standard polystyrene with a molecular weight of 37,000 ; No. $2-5$ and 7 are poly(CB-co-St)s (see Table I).

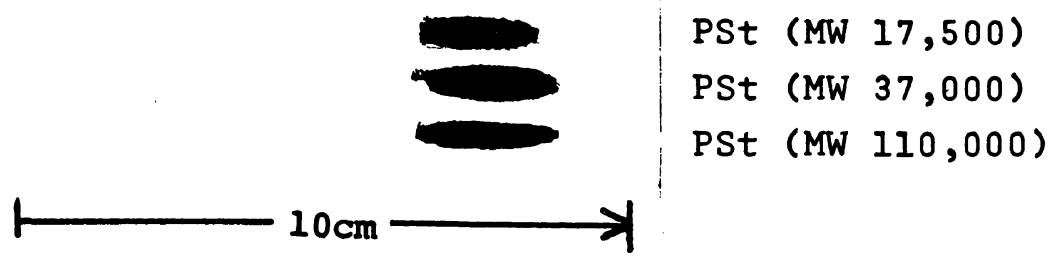

Figure 2. TLC of polystyrenes: polystyrenes are commercially available and have a narrow molecularweight distribution; their molecular weights are indicated in parentheses.

i.e., a narrower distribution than No. 7. Since No. 2-5 were obtained at conversions lower than No. 7 (see Table I), the compositional heterogeneity of these copolymers should be narrower than No. 7 . The CB content of No. 7 was similar to that of No. 3 , and had the molecular weight of the polymers. Thus, the TLC separations in Figure 1 are considered due to compositional heterogeneity and not to molecular weight.

To prove this, a TLC study on the poly(CB-co$\mathrm{St}$ )s of the same molecular weight but of different composition is necessary. Unfortunately, the CB content in the monomer feed is a determining factor for the molecular weight of poly(CB-co-St $),{ }^{1}$ and it is difficult to synthesize such poly(CB-co-St)s. To check the effects of molecular weight, three standard PSts of different molecular weight were subjected to TLC separation by gradient development. The results are shown in Figure 2, and indicate that separation according to molecular weight is insignificant in the present TLC development.

The shape of the spots for poly(CB-co-St)s differs from that of PSts, and PSts have larger $R f$ values. These facts suggest the formation of a true co-
Table V. Compositional Distribution in poly(CB-co-St)s

\begin{tabular}{ccc}
\hline & \multicolumn{2}{c}{ CB content in copolymer $/ \mathrm{mol} \%$} \\
\cline { 2 - 3 } & Experimental $^{\mathrm{a}}$ & Theoretical $^{\mathrm{b}}$ \\
\hline 6 & $0.0-8.2$ & $0.2-7.7$ \\
7 & $0.5-11.8$ & $0.4-11.1$ \\
8 & $1.4-16.0$ & $0.8-14.1$ \\
9 & $2.1-20.7$ & $1.0-16.9$ \\
\hline
\end{tabular}

a From TLC.

${ }^{b}$ Calculated from $r_{\mathrm{CB}}=1.680, r_{\mathrm{St}}=0.274,{ }^{1}$ and conversion by the Skeist method. ${ }^{7}$

polymer of CB and St. From the chromatograms, we could determine the compositional distribution of samples No. 6-9, obtained at high conversions. From the monomer reactivity ratios ${ }^{1}$ and conversion, the compositional distribution was calculated. ${ }^{2,7}$ Both the experimental and theoretical distributions are shown in Table $\mathrm{V}$ and seem in close agreement. In Table $\mathrm{V}$, only the compositional ranges are shown, since the observed TLC 
spots were oval and not the average composition values; the compositional distribution is our main concerns here.

The agreement shown in Table $\mathrm{V}$ supports the copolymerization kinetics applied to CB-St copolymerization and the validity of the monomer reactivity ratios based on the terminal model. ${ }^{1}$ It is evident, however, that the chromatograms of poly(CB-co-St)s show some tailing which is direct proportion to the $\mathrm{CB}$ content in the copolymer. Adsorption chromatography of the polymers usually gave oval spots due to some heterogeneity. In the CB-St copolymers, this distortion was enhanced. Considerable experimental work was carried out to eliminate the distortion, but without success. To ascertain the copolymerization kinetics further, another method, such as determination of monomer

Table VI. Mixing mode in the THFcyclohexane concentration gradient development $^{\text {a }}$ for low CBcontent poly(CB-co-St)

\begin{tabular}{|c|c|c|}
\hline Distance from the origin ${ }^{b}$ & THF & Cyclohexane \\
\hline $\mathrm{cm}$ & $\mathrm{ml}$ & $\mathrm{ml}$ \\
\hline 0 & 0 & 50 \\
\hline 2 & 10 & 50 \\
\hline 4 & 20 & 50 \\
\hline 6 & 30 & 50 \\
\hline 8 & 40 & 50 \\
\hline
\end{tabular}

a At room temperature: Stationary phase; Kieselgel $\mathrm{H}$ Typ $60,0.4 \mathrm{~mm}$.

b Development was conducted at a distance of $10 \mathrm{~cm}$ from the origin. sequence distribution in the copolymer may be necessary, using the NMR technique or some other method.

\section{Determination of Small Amounts of $C B$ in the Copolymer \\ Copolymers No. 10 and 11, obtained with very} low $\mathrm{CB}$ content in the monomer feed, contained no CB units according to the usual elemental analysis (see Table I). Apparently these two copolymers were not homopolystyrene but rather poly(CB-co$\mathrm{St}$ )s with amounts of $\mathrm{CB}$ too small to permit assaying by ordinary elemental analysis. For the determination of the composition of poly(CB-co$\mathrm{St}) \mathrm{s}$, elemental analysis has been found most reliable $^{4}$ and the values as obtained coincide very well with those by ${ }^{1} \mathrm{H}$ NMR method. ${ }^{4,8}$ However, the lowest limit of chlorine weight $\%$ happens to be $0.2 \%$ by the usual elemental analysis, a value equivalent to $0.588 \mathrm{~mol} \% \mathrm{CB}$ in poly(CB-co-St). Samples No. 10 and 11 may possibly contain $c a .0 .5$ $\mathrm{mol} \% \mathrm{CB}$.

By TLC, we determined the CB units in No. 10 and 11 , since it is known to be very sensitive toward the presence of polar groups in nonpolar molecules, ${ }^{3,5}$ and does not require the use of expensive instruments and can be carried out easily. To achieve the best separation in lower CB-content regions, many TLC experiments were performed and the mode of gradient development shown in Table VI was adopted and the TLC results in Table VII. The TLC spots of these samples (except no. 7) were oval but not very wide or as distorted as those of the samples in Table $\mathrm{V}$. Therefore, the middle points of the spots were used to determine the CB

Table VII. Composition determination by TLC for poly(CB-co-St)s, No 10 and $11^{\mathrm{a}}$

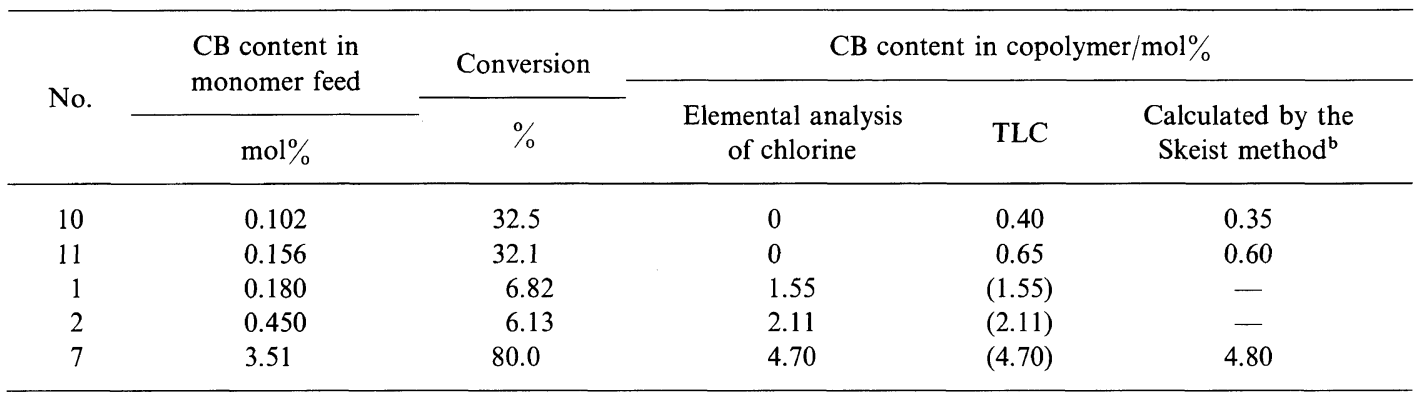

a See Table I.

b Theoretical values from monomer reactivity ratios and conversion by the Skeist method. ${ }^{7}$ 


\section{S. KoHJiYa et al.}

content in the samples. For No. 7 a CB content of $4.70 \mathrm{~mol} \%$ was obtained from the middle point of the blackest part of the spot. No. 1, 2, and 7 were used as standards for TLC analysis. The observed values for No. 10 and 11 were in close agreement with those calculated, even though the amount of which were too small by usual elemental analysis. The agreement of the values obtained by elemental analysis with those calculated for No. 7 supports the validity of determination by TLC for No. 10 and 11 .

These results support the claim of Inagaki et al. ${ }^{3}$ made in 1968, i.e., "copolymers consisting of various polar and nonpolar monomers can be resolved successfully by TLC," and show the remarkable sensitivity of the TLC method toward small amounts of polar groups in nonpolar macromolecules. However, this may be a drawback when applied to polymers containing larger amount of polar groups. For example, in Table II, No. 2 (CB, $2.11 \mathrm{~mol} \%$ ) and No. 3 (CB, 4.58 $\mathrm{mol}^{\circ} \%$ ) show somewhat different behavior, but for No. 4 (CB, $12.8 \mathrm{~mol} \%$ ) and No. 3, the results are almost the same. For the same reason, determination of compositional distribution by TLC may be somewhat limited. Generally speaking, cross fractionation is the most reliable method for determining compositional heterogeneity, but is too time consuming and not always practical for diene polymers which are subject to oxidation in the air. Therefore, in its place, TLC is very good for determining compositional heterogeneity, and consequently may be useful for polymer characterization.

\section{REFERENCES}

1. S. Kohjiya, M. Kurokawa, K. Iwata, Y. Imoto, and S. Yamashita, Polym. J., submitted.

2. H. Inagaki, Adv. Polym. Sci., 24, 189 (1977).

3. H. Inagaki, H. Matsuda, and F. Kamiyama, Macromolecules, 1, 520 (1968).

4. Preliminary report on this subject was published: $\mathrm{S}$. Kohjiya, K. Iwata, S. Yamashita, T. Miyamoto, and H. Inagaki, Colloid Polym. Sci., 258, 1192 (1980).

5. See ref 2 and L. R. Snyder, "Principles of Adsorption Chromatography," Marcel Dekker, New York, N.Y., 1968.

6. S. M. Rybicka, Chem. Ind. (London), 308 (1962).

7. I. Skeist, J. Am. Chem. Soc., 68, 1781 (1946).

8. S. Kohjiya, H. Takeuchi, K. Kawamoto, and S. Yamashita, Bull. Chem. Soc. Jpn., 54, 3245 (1981). 